\title{
Development of land use transitions research in China
}

\author{
LONG Hualou ${ }^{1,2}$, "QU Yi”, TU Shuangshuang ${ }^{1,4}$, ZHANG Yingnan ${ }^{1,2}$, \\ JIANG Yanfeng ${ }^{1,5}$
}

1. Key Laboratory of Regional Sustainable Development Modeling, Institute of Geographic Sciences and Natural Resources Research, CAS, Beijing 100101, China;

2. College of Resources and Environment, University of Chinese Academy of Sciences, Beijing 100049, China;

3. School of Geography, Geomatics and Planning, Jiangsu Normal University, Xuzhou 221116, Jiangsu, China;

4. Key Laboratory of Environment Change and Resources Use in Beibu Gulf, Nanning Normal University, the Ministry of Education, Nanning 530001, China;

5. School of Geographical Sciences, University of Nottingham Ningbo, Ningbo 315000, Zhejiang, China

\begin{abstract}
With the introduction of the concept of land use transition into China, related researches have been carried out extensively in the past two decades, which enrich the knowledge of land system science. This paper describes the development of research on land use transitions in China from the perspectives of conceptual connotations, theoretical model, research methods, and research progress and prospects. With the in-depth investigation of land use transitions, the concept and connotations of land use morphology are developed and encapsulated as two kinds, i.e., dominant morphology and recessive morphology. The dominant morphology refers to the land use structure of a certain region over a certain period of time, with features such as the quantity and spatial pattern of land use types. While the recessive morphology includes the land use features in the aspects of quality, property rights, management mode, input, output and function. Accordingly, the concept of land use transition is further developed, and the theoretical model of regional land use transitions is established. Thereafter, three innovative integrated approaches to study land use transitions are put forward, i.e., multidisciplinary research framework for recessive land use transition, transect and horizontal comparison. To date, there have been 62 Ph.D. and 166 M.S. dissertations on the topic of "land use transition" in China. During 2002-2019, the National Natural Science Foundation of China has funded 48 research programs on the theme of "land use transition". As such, the Chinese scholars have adapted the concept derived from western literature to the situations and experiences in China.
\end{abstract}

Keywords: land use morphology; theoretical model; multidisciplinary integration; horizontal comparison; rural restructuring; rural vitalization; land system science

Received: 2019-12-08 Accepted: 2020-04-16

Foundation: Key Program of National Natural Science Foundation of China, No.41731286

Author: Long Hualou (1971-), $\mathrm{PhD}$ and Professor, specialized in rural restructuring, urban-rural development and land use transition. E-mail: longhl@igsnrr.ac.cn

"Corresponding author: Qu Yi (1986-), PhD, specialized in rural development and land use.

E-mail: quy.13b@igsnrr. ac.cn 


\section{Introduction}

Land use transition is one of the manifestations of land-use change (Long et al., 2007), and is also one of the major research contents of Global Land Project (GLP), a joint research agenda of the International Geosphere-Biosphere Programme (IGBP) and the International Human Dimensions Programme on Global Environmental Change (IHDP) to improve the understanding of land system dynamics (GLP, 2005). Land use transition was put forward by Grainger $(1986,1995)$ based on his study on the land use in forested countries. From then on, the research concerning land use transition has been carried out vigorously, but which still mainly focused on forest transition (Mather et al., 1999; Meyfroidt and Lambin, 2008; Barbier et al., 2010).

Although pieces of evidence supported the original forest transition hypothesis and trajectories, there were still some researches that showed different opinions. For example, it showed that forest cover change involves complex trajectories, some of which are cyclical and reversible, while others are linear and permanent. Barbier et al. (2010) developed a more comprehensive theory of the forest transition and argued that long-run changes in forest cover in a country or region cannot be separated from the national or regional pattern of land use changes, taking into account of the competition among different land use. The research of land use transitions including forest transition has been the foci of studying land change science since the turn of the new millennium (Long et al., 2007; Lambin and Meyfroidt, 2010; Rudel et al., 2010), ranging from those who favor the development of analysis methods and detection technologies (Ferreira et al., 2015), the dynamic driving mechanism ( Liu et al., 2008; Jadin et al., 2016), the environmental effects (Nuissl et al., 2009; Long, 2014a; Qu and Long, 2018a), to those who try to understand the relationship between land use transitions and socio-economic development (Lambin and Meyfroidt, 2010; Chen et al., 2014).

Accelerated urbanization and subsequent increase of human activities are triggering tremendous land use transitions in China. With the introduction of land use transition research into China (Long, 2001, 2003; Long and Li, 2002), related researches combining land use transitions with the sustainability of socio-economic development have been carried out extensively, which enrich the knowledge of land system science. The objective of this paper is to describe the development of research on land use transitions in China from the perspectives of conceptual connotations, theoretical model, research methods, and research progress and prospects, showing how a concept derived from western literature has been adapted to the situations and experiences in China.

\section{Conceptual connotations}

Foley et al. (2005) pointed out that land use transition is not only a regional issue but also of global significance. Different regions are in different stages of transformation development due to historical, socio-economic and ecological conditions, and political institutions. Not all regions follow a linear transformation development, and some regions also exhibit a non-linear trajectory. A certain area may stay longer in a certain stage, and some areas may be shorter in the corresponding stage. Meyfroidt et al. (2013) and Lambin (2012) argued that the driving forces of land use transition are not only confined to socio-economic distur- 
bances and natural background factors in one region, but also affected by the displacement effect produced by international trade. Globalization and urbanization are two important global trends since the middle of the 20th century. As a result of their interaction, a complex trade network has gradually formed between countries, thus forming an important tele-coupling context of land use transitions.

Land-use and land-cover change (LUCC), as the core of coupled human-environment systems, has become a potential field of land change science (LCS) in the study of global environmental change ( $\mathrm{Li}, 2002$; Liu et al., 2010). The goal of GLP is to measure, model and understand the coupled socio-environmental terrestrial system, which is also referred to as "land system" (GLP, 2005). Land use transition is the changes in land use morphology, the overall pattern of actual land cover in a region at a given time, over time (Grainger, 1995). Land use morphology is the key content of land use transition research. Driven by socio-economic change and innovation, only focusing on the quantity and spatial structure characteristics of land use morphology cannot meet the demands of the research on land use transition (Lambin and Meyfroidt, 2010). As such, the concept and connotations of land use morphology need to be developed continuously with in-depth research and socio-economic change and innovation.

Based on the analysis of the evolvement of the concept and connotations of land use morphology, we argue that there are two formats for depicting land use morphology: one is dominant morphology, another is recessive morphology. The dominant morphology refers to the land use structure of a certain region over a certain period of time, with features such as the quantity (area, proportion) and spatial pattern of land use types. The recessive morphology is a special morphology which relies on the dominant morphology but can only be observed by the means of analyzing, testing, monitoring and surveying, includes the land use features in the aspects of quality (nutrient, pollution, degradation), property rights (state-owned, collective-owned), management mode (individual, joint-stock system, transfer and large-scale management), input (capital, technology, labor), output (yield, output value, input-output ratio) and function (production, living, ecology, culture). So, the conception of land use transition may be further developed as follows: land use transition refers to the changes in land use morphology, including dominant morphology and recessive morphology, of a certain region over a certain period of time driven by socio-economic change and innovation, and it usually corresponds to the transition of socio-economic development stage (Long and Li, 2012; Long and Qu, 2018).

\section{Theoretical model}

Land use transition is a new theme of the comprehensive research of LUCC (Long, 2003), the concept of which was first introduced into China with an initial meaning of temporal changes in land use morphology corresponding to socio-economic development transition, and the land use morphology means mainly the quantity and spatial structure characteristics of land use in a region at a given time (Grainger, 1995; Long and $\mathrm{Li}, 2002$ ). The national/regional land use morphology corresponds to its socio-economic development stage, that is, the specific socio-economic development stage is associated with a certain land use morphology (Grainger, 1995). National/regional land use patterns are not static, they vary 
with socio-economic development. For example, land use patterns in the U.S. in the late 20th century indicate that the proportion of forest land and grassland is almost the same as the world average, but it has changed greatly compared with the previous stages (Grainger, 1995).

To some extent, the regional land use transitions are essentially a process during which different land use types which represent the benefits of different departments conflict in space dimension, and the stakeholders try to alleviate these conflicts by changing the morphologies in time dimension. Accordingly, the theoretical model of regional land use transitions is put forward as follows: with the economic and social development, transformations between different land use types during a certain period of time cause the change of the conflicts resulted from changed regional land use morphology pattern from strong to weak, i.e., a trend towards coordination; these transformations will lead to a new balance of regional land use morphology pattern consists of different land use types which reflect the development trend of corresponding economic departments, respectively, and finally realize the qualitative transformation of urban-rural land use system (Long and $\mathrm{Qu}, 2018$ ).

Land use transition refers to the changes in regional land use morphology, and the regional feature is an important aspect of land use transition research. Strictly speaking, the transformation of single land use type, e.g., farmland was changed to forest land, cannot be treated as land use transition, which can only be treated when it is put into the context of regional land use structure and function to analyze the changes of land use morphology (Long, 2015).

Usually, the process of land use transitions comprises long-term and trend changes in regional land use morphology. The fundamental change of land use morphology or the turn of its changing direction indicates an accomplishment of land use transitions in a certain period. New land use issues arise with the economic and social development will bring about new conflicts of regional land use morphology patterns, thereafter a new regional land use transition process will be triggered. Currently, there are abundant researches on the dominant morphology of regional land use but less on the recessive morphology. However, land use transitions in the aspect of recessive morphology are most closely relative to land use management. The process and outcome of land use transitions may improve land management policies and measures (Long and $\mathrm{Qu}, 2018$ ). On the contrary, land use transitions may be deeply affected by the adjustment of existing policy or the implementation of a new land use policy.

\section{Research methods}

In the aspect of qualitative research of land use transitions, hypothesis-deduction method is commonly used since the trend of land use transitions is uncertain, to some extent. Harvey (1969) mentioned that in his book "Explanation in Geography", there are two approaches to scientific interpretation: inductive and deductive methods. Among them, deductive method is more commonly used. The structure of the real world, based on the prior model (the formal representation of the image), is abstracted, and then a theory can be assumed. Afterward, the functional-perceived data can be compared with a posterior model (another way of expressing the concepts contained in the theory, such as using mathematical symbols) and used 
to test the hypotheses (Harvey, 1969). It is testified that the deductive method is helpful for theorizing land use transition (Long et al., 2007).

Another common method is corresponding systematic comprehensive analysis, which was put forward by Chen (1998) who emphasized the corresponding transformation analysis of regional natural structure and productivity layout, as well as the production, sales, and consumption structure, which pioneered a new way of formulating regional development strategy at county level (Chen, 1998). This research method can provide a scientific basis through the structural correspondence analysis and comparative study of physical-ecological structure, technical-economic structure, social-political structure in a region, which can be used for reference in the research of land use transitions. Temporal changes and historical backgrounds of social and environmental variations can be integrated through comprehensive system analysis.

It is generally known that mathematical models and 3S (GIS/RS/GPS) technologies have the advantages for carrying out quantitative research of land use transitions, especially in the aspect of dominant morphology of land use. However, it is pivotal to have a tendency to turn to multidisciplinary integration method for the research of recessive morphology of land use. Based on the above analysis, we put forward three innovative integrated approaches to study land use transitions, i.e., multidisciplinary research framework for recessive land use transition (Qu and Long, 2018b), transect research method (Long et al., 2007), and horizontal comparison research method (Long, 2003; Long et al., 2007).

\subsection{Multidisciplinary integration}

\subsubsection{Conceptual framework of multidisciplinary research}

The connection between different disciplines should be based on theoretical reference, by means of method connection and bridged by software and data format connection. The purpose is to analyze and mine the results from different perspectives. Theory is the basis of discipline development. The mutual reference of different discipline theories can provide direction and guidance for problem analysis (Cai, 2001; Fan, 2019). In terms of methods, different disciplines have their own preferred research methods, which come with both strengths and weaknesses. For example, spatial analysis and system analysis are frequently used in geography, but there is a lack of a validation mechanism for the analysis results. Econometrics is good at statistical analysis, but it lacks the comprehensive analysis mechanism of multiple factors at different spatial scales. Therefore, they can complement one another. Technically, the established research methods need to be realized by corresponding software technology, data acquisition technology, and analysis technology, and the selected research methods need to be adjusted appropriately, according to the technical feasibility of the research process. In terms of results, multi-dimensional analysis results can be obtained through the connection of analysis technologies of different disciplines (Cai, 2001; Fu, 2014). Meanwhile, from the perspectives of different disciplines, these results can be further mined and analyzed. In the overall analysis process, the mutual reference and development of theories are the basis of the result analysis (Qu and Long, 2018b): without theoretical guidance, the data analysis results could be easily biased or even wrong; meanwhile, rigorous analysis results and research conclusions play an important role in promoting the development and improvement of theory, because the development of theory comes from practice, 
and theory is a general summary of many individual phenomena in practice (Figure 1).

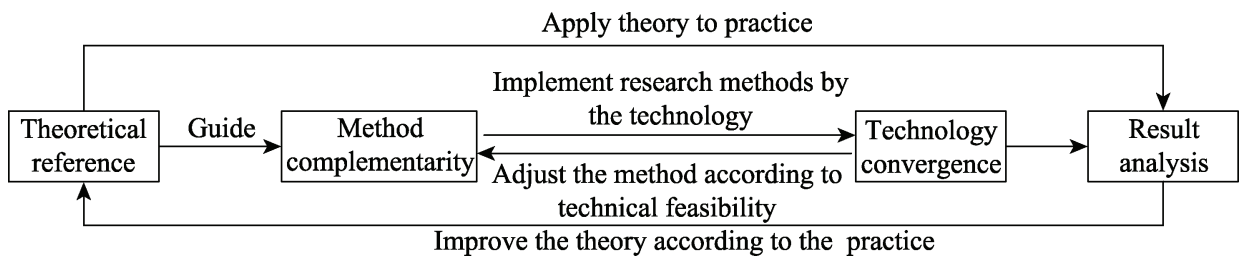

Figure 1 The conceptual framework of multidisciplinary research (Adapted from Qu and Long, 2018b)

\subsubsection{Specific design of multidisciplinary research}

Under the guidance of the above conceptual framework, the comprehensive research framework of the disciplines involved in the research into the recessive land use transition was specifically designed (Figure 2). At the theoretical level, research into the recessive transition of land use mainly involves disciplines including geography, management, economics, and sociology (Qu and Long, 2018b). With the research problem-oriented approach, preliminary reference and integration of different theories can be attempted. For example, to study moderate-scale land use management in China, based on "the man-land interrelations territorial system theory" in geography, the regional differentiation rules of natural factors and the differentiation characteristics of socio-economic factors in different regions are outlined. Then, based on the scale economy theory and production theory in economics, quantitative analysis of specific regions can be carried out to explore moderate-scale management in accordance with local conditions.

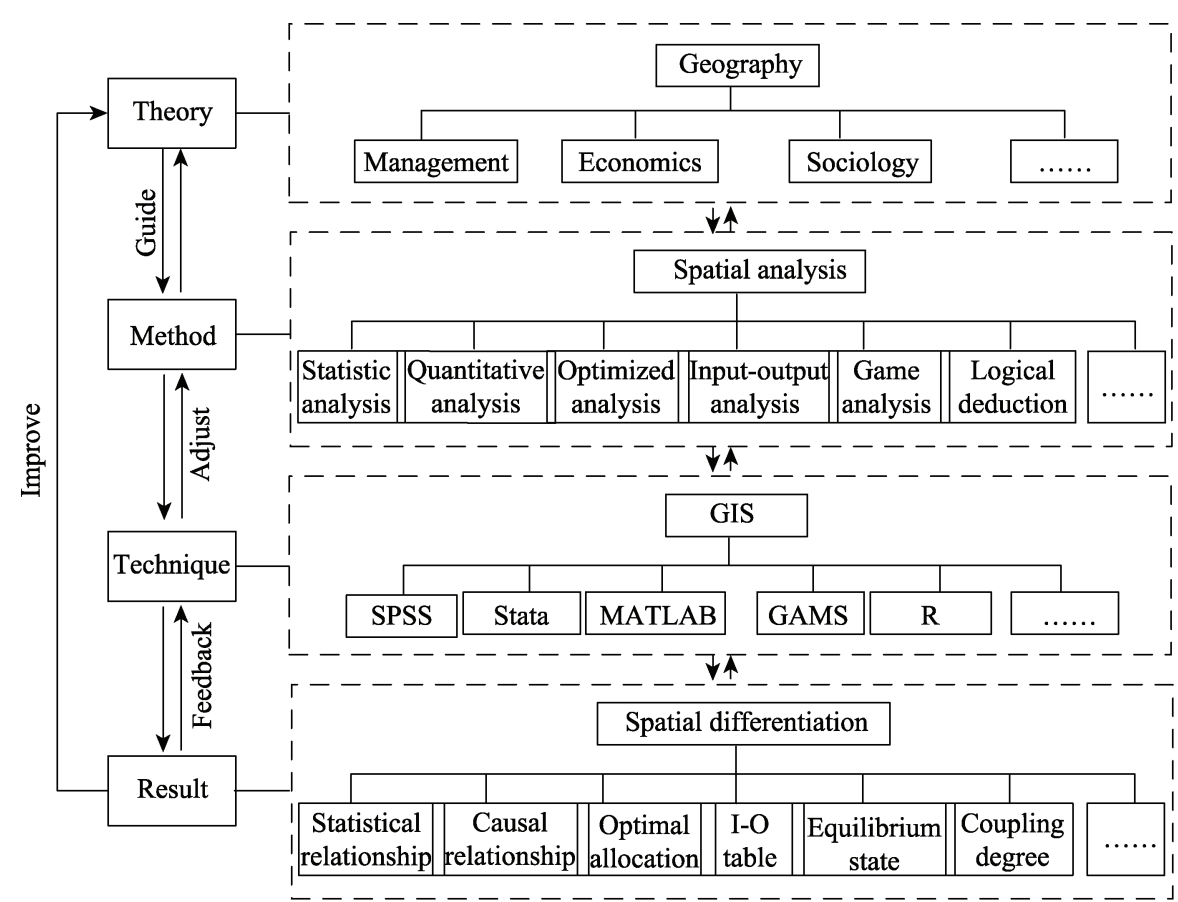

Figure 2 The specific design of multidisciplinary research (Adapted from Qu and Long, 2018b) 
At the methodological level, spatial analysis is frequently used in geography, and measurement and input-output analysis are common methods in economics. Qualitative logic deduction and quantitative statistical analysis methods are commonly used in management and sociology. The above methods can complement each other to meet the needs of multi- dimensional and multi-angle analysis in terms of time (stage), space, and quantity (Qu and Long, 2018b). For example, to analyze the choice of management mode in a specific region, we can perform qualitative analysis and make logical deductions about local policies, resource endowments, and mainstream characteristics to obtain plan options from the perspectives of management and sociology. Then, based on the field survey data, a quantitative measurement can be carried out to determine the final plan from the perspective of economics.

At the technical level, there needs a dual connection between different analysis softwares and different analysis data (Qu and Long, 2018b). Through spatial analysis using GIS related softwares, a preliminary analysis results can be obtained. The results could be exported to the SAV format (read by SPSS) to realize the statistical analysis of spatial information, to the DTA format (read by Stata) to realize the quantitative analysis of spatial information, to the DAT format (read by MATLAB) to realize the mathematical optimization analysis of spatial information.

At the result level, we can obtain the statistical relationship (such as correlation and duality) between different elements through statistical analysis and the causal relationship between different elements through quantitative analysis. Also, through mathematical optimization analysis, we can analyze the optimization relationship among the input ratios of various elements under different restrictions. Through the input-output analysis, the interrelationships between resource input and economic output can be obtained. Through game theory analysis, an equilibrium state of the decision-making among different activity types can be obtained. Based on the above multi-means, multi-perspective, and multi-angle analysis, we can obtain the comprehensive cognition of the research object from development status, evolution laws, and future trends (Qu and Long, 2018b).

4.1.3 A case of multidisciplinary research framework for recessive land use transition

The following questions need to be answered in the study of the recessive transition of land use: what is the recessive morphology of land use at different times or stages? What are the recessive transition patterns of land use in different regions? What is the transition mechanism between different recessive morphologies of land use? What kinds of economic effect, social effect, and environmental effect will be caused by different recessive transitions of land use? The above problems involve different disciplines, such as geography, management, economics, and so on. So only with comprehensive analysis from different dimensions with the integration of various disciplines, could these researches be successfully completed. In order to determine the type of land use transition to be taken in a given region, and the measures to be taken to guide the implementation, a comprehensive analysis should be conducted from multiple dimensions of time (stage), space, and quantity (Figure 3). The analysis process is similar to finding a point in a cube that satisfies three-dimensional conditions. When only a single dimension is considered, even if the information in this dimension is very accurate, the conclusions can only be specified to one plane. When considering the information in two dimensions, the conclusions could be narrowed down to a line, but there is 


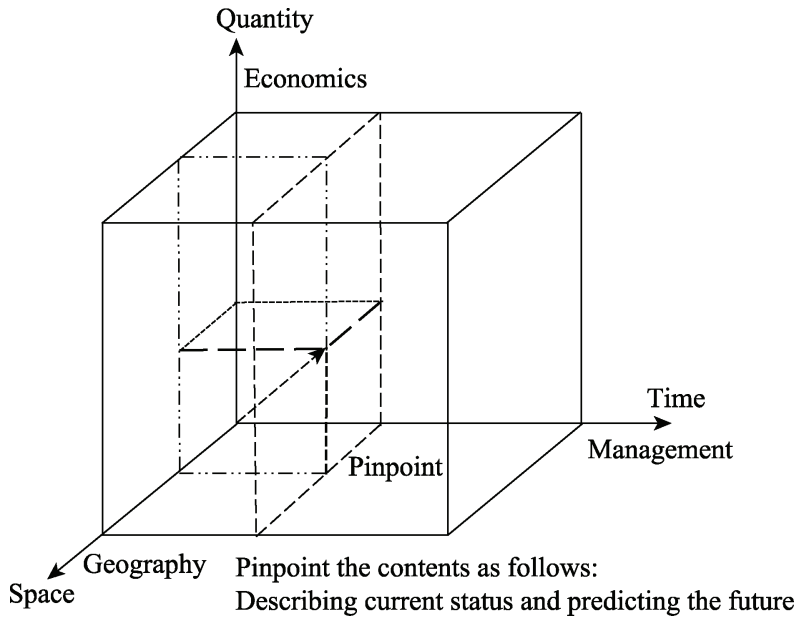

Figure 3 A multidisciplinary research framework for recessive land use transition (Adapted from Qu and Long, 2018b)

still great uncertainty. Only by considering comprehensive information in three dimensions can we obtain pertinent and reliable research conclusions (Qu and Long, 2018b).

For example, quantitative analysis is frequently used in econometrics. However, if the production efficiency of different management scales is only analyzed from the quantitative dimension, and factors such as the differences in the natural conditions of different regions and the market levels of factors at different economic stages are ignored, it will lead to the coexistence of "positive," "reverse," and "non-linear" conclusions. At present, even the "inverse relationship" with a strong empirical basis is controversial. Some scholars have argued that the "inverse relationship" did not follow the objective law, as the imperfection of the factor market was ignored in the analysis (Heltberg, 1998). Some scholars believed that it was caused by the omission of important natural difference variables (Chen et al., 2011). And others denied the above reasons to support the existence of such a law (Calogero et al., 2013). The reason why different views exist is that the analysis process cannot be comprehensively investigated within a unified framework, which leads to biased conclusions. For another example, spatial pattern analysis is commonly used in geography. However, if we only analyze the spatial pattern of the climate, soil, labor, and crop planting, the specific process of land use transition cannot be effectively detected. Meanwhile, it is also impossible to extract a transition mode that accords with the quantitative law of production and could be incorporated it into practice effectively. Therefore, research into the recessive transition of land use needs comprehensive research from multiple disciplines and perspectives. Details of this are described as follows (Qu and Long, 2018b).

Management can provide a macro time (stage) background for research from the time (stage) axis. For example, with technological development and institutional changes, what kinds of changes have taken place in the policies for land use and agricultural production? What changes have taken place in the property rights of land? How will the land use management mode and type evolve? From the time (stage) dimension, the research problem can be specified to a plane, which clarifies the problem definition.

Geography can provide regional background for research from the spatial axis. For example, with the change of natural zone, what is the spatial evolution law of natural factors, such as daylight, temperature, soil, and water? What are the spatial differences in the abundance of land resources, farmland quality, and cropping system? What is the spatial distribution of the land production function and ecological function? What is the spatial transfer pattern of the agricultural labor force? What is the spatial differentiation of the agricultural development level? As the regional characteristics of research objects were figured out, the research problem can be further specified from a plane to a straight line. 
Economics can give more accurate positioning from the quantitative axis. For example, in a given region with a relatively uniform policy background, development stage, and natural economic characteristics, analysis can be conducted on the variation characteristics of efficiency indicators, such as land (or household, labor) production efficiency (physical or value), technical efficiency, total factor productivity with different conditions of management scale, management mode, and management type. After defining the specific position in the quantitative axis, the research problem is further specified to a certain point on the straight line, so the conclusion is more specific and reliable.

\subsection{Transect}

The terrestrial transects of IGBP emphasize on explaining issues concerning global change through gradient methods, and temperature, precipitation and land use are three key gradient factors (Koch et al., 1995). We can use this transect as a coherent set of study sites to determine how land-use associated land-cover is changing as a result of social and environmental factors, and how these changes interact with biophysical factors (Koch et al., 1995). Usually, land use change is triggered by socio-economic factors (Li, 1996; Cai, 2001; Krausmann et al., 2003). Therefore, the socio-economic developmental level was considered the most important factor to define a case area for studying land use transitions.

Here, Transect of the Yangtze River (TYR) is taken as an example (Long et al., 2007). In the Yangtze River Valley, we have identified a Transect in which the underlying gradient is the changing pattern of land use. The level of socio-economic development is sharply declining from the East of the Yangtze Transect to the West. It comprises an area of about 1.12 $\mathrm{M} \mathrm{km}$, containing 312 counties (or cities at county level), which belong to the following 11 provincial-level regions-Shanghai, Jiangsu, Anhui, Jiangxi, Hubei, Hunan, Chongqing, Sichuan, Yunnan, Qinghai and Tibet. Along the Transect, there are several of the biggest cities in China-Shanghai (to the East), Nanjing (the capital of Jiangsu province), Wuhan (the capital of Hubei province) and Chongqing Municipality. TYR is about $3600 \mathrm{~km}$ in length, with an average width of $200 \mathrm{~km}$ or so.

\subsection{Horizontal comparison}

Land use transitions are often studied based on long time series statistics. Although global environmental data have grown in abundance in recent decades, time-series data for China are unreliable, because the statistical system was disrupted several times since it was founded in 1949 by several campaigns that hampered economic development, such as Great Leap Forward (1958-1960) and Cultural Revolution (1966-1975). However, China has a vast territory with obvious regional differentiation in the level of socio-economic development, which makes it possible to apply a spatial comparative research method to study land use transitions. This method is called as horizontal comparison research method, i.e., using the spatial differentiation in regional development to compensate data deficiencies in the long time series, reflecting the change process of land use with space to exchange for time (Figure 4). The application of horizontal comparison combining with the transect method was used to study rural housing land transition in the transect of the Yangtze River (Long et al., 2007). 


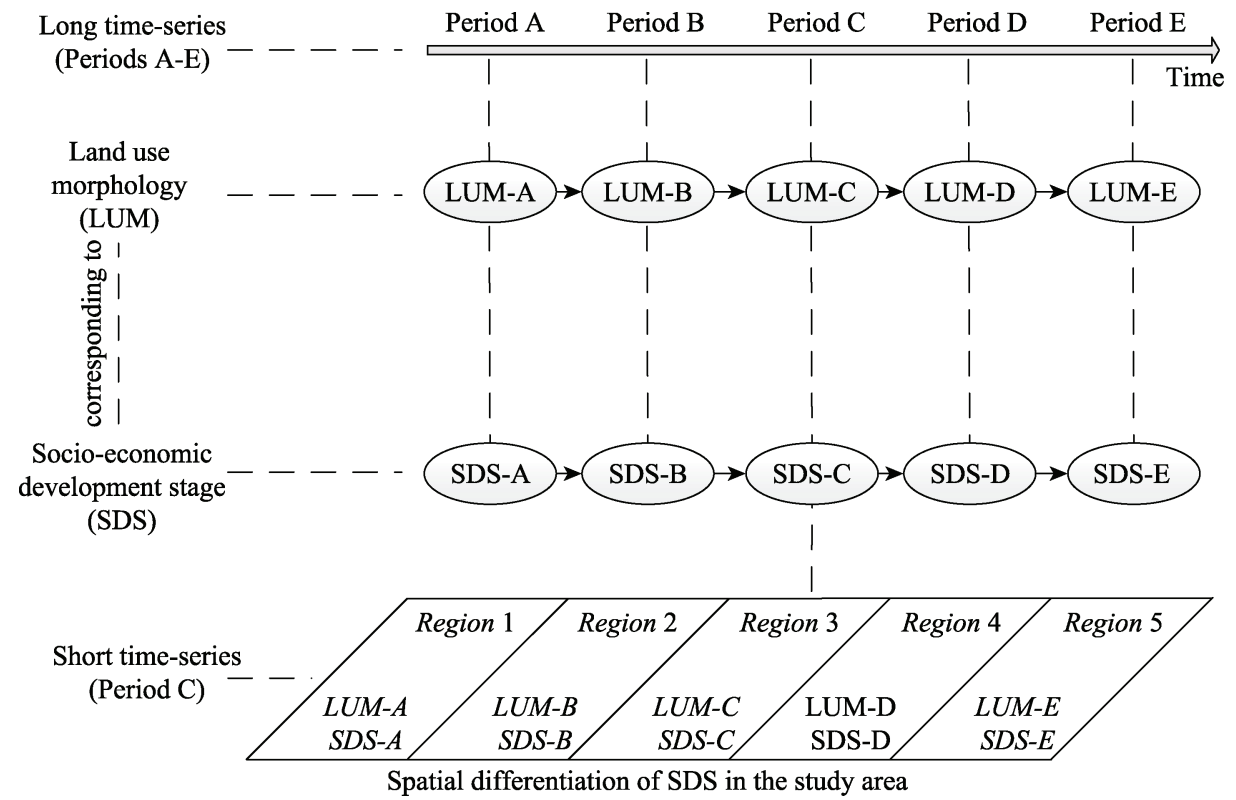

Figure 4 A sketch map of horizontal comparison research method with space to exchange for time

Recent years have witnessed the widespread use of novel methods incorporating quantitative analysis, integrated " $3 \mathrm{~S}$ " technology, and transect. Introducing the transect to longitudinal comparison can overcome the deficiencies of time series data combined with the above-mentioned horizontal comparison research method, which is of great significance for the researches of land use transitions and rural development in China. For example, the research team of agricultural geography and rural development of Chinese Academy of Sciences, has selected Transect of the Yangtze River, "Southern Jiangsu-Northern Shaanxi" Transect, and Transect along No.106 State Road to carry out related studies (Long et al., 2007, 2012b; Lu and Liu, 2013).

\section{Research progress}

Recently, related researches on land use transitions combined with the characteristics of China's socio-economic development have been carried out rapidly since the research field of land use transition was introduced into China. Over the last decade, the research on land use transitions has flourished in China and involved various aspects, e.g., related concept (Lu et al., 2006), the laws (Cai et al., 2009; Song et al., 2015), and the research framework (Long, 2012a; Song, 2017; Hu et al., 2019a), theory and hypotheses (Long et al., 2007; Song and $\mathrm{Li}, 2019$ ) of land use transition, the transition of the land use mode and structure (Liu and $\mathrm{Li}, 2006$ ), the transition of a particular land-use type (Long et al., 2007; Kong, 2012; Ma et al., 2020), the economic and environmental effects of land use transitions (Long et al., 2018a, 2018b; Qu and Long, 2018a), and the relationship between land use transitions and other land-use activities (Chen et al., 2014, 2020). The editor set up a special column of 'Land use transition' in the special issue of "Land Use Policy in China" published by the journal of Land Use Policy (Long, 2014b).

To date, there have been 62 Ph.D. and 166 M.S. dissertations on the topic of "land use 
transition" in China, as shown by the statistics from Database of Dissertations of Ph.D. and Master Degree in China National Knowledge Infrastructure (CNKI) and Thesis \& Dissertation Database of Chinese Academy of Sciences. Since 2011, "land use transition" has been selected as one of the keywords in the research field of "rural land use and allocation" under the discipline of Human Geography, which is a significant research branch of the National Natural Science Foundation of China (NSFC). During the period of 2002-2019, the NSFC has funded 48 research programs on the theme of "land use transition", which included one key program. In 2015, A Non-profit Industry Financial Program entitled "Management and Control Technologies and Policy Innovation of Land Use Transitions in the Middle Reaches of the Yangtze River Economic Belt" was granted by the Ministry of Land and Resources of China (MLRC), which demonstrated that land use transition has sparked great concern in both academic communities and the governmental authorities since it was introduced into China in 2001 (Figure 5).

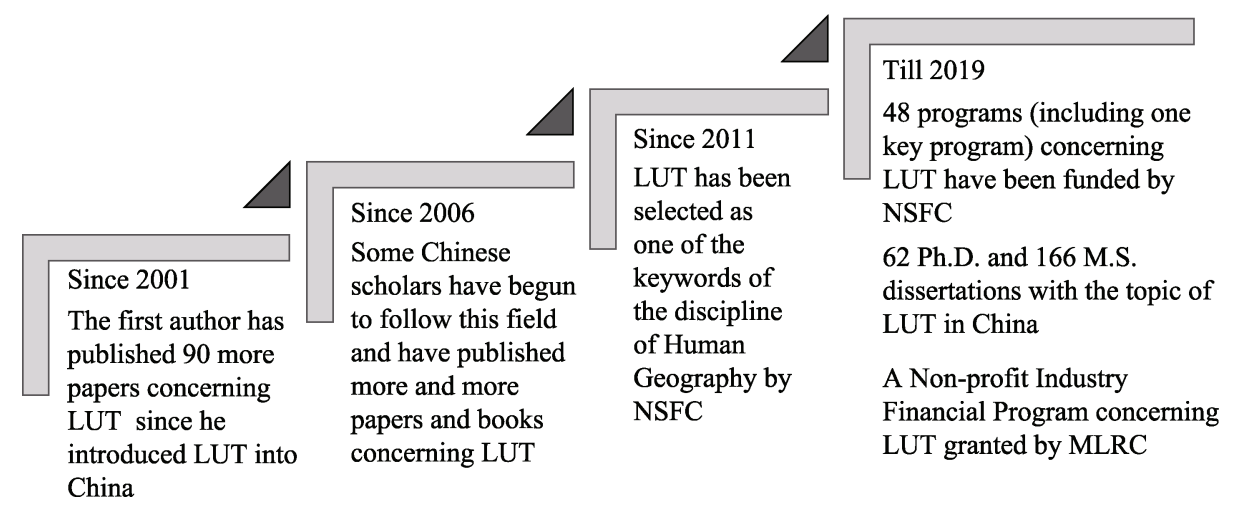

Figure 5 The development of land use transition (LUT) research in China

Farmland and rural housing land are the two major land-use types closely related to human livelihood and production activities. It is well known that the urban is originally developed from the rural, and its formation and further development is closely linked with the transition of farmland and rural housing land. In general, socio-economic development affects land use morphology, which also makes a counteraction to socio-economic development. The interaction between land use morphology and socio-economic development facilitates the land use transition. Therefore, the changes in the regional land use morphology may be basically reflected by the changes in farmland and rural housing land, two major land-use types affecting human production activities. Farmland and rural housing land, as the two major sources of land use transitions, play an important role in the process of facilitating land use transition. Recently, Chinese scholars have paid much attention to farmland transition, rural housing land transition and their relationships with rural restructuring under the policies context of urbanization, industrialization, 'Building the New Socialist Countryside' and subsequent 'Rural Vitalization' (Long et al., 2010, 2019; Long, 2020).

\subsection{Farmland use transition}

When considering the quantity change of farmland, if, at a certain time, the change in the area of farmland presents a turning trend, indicating that the spatial morphology of farmland has changed. After socio-economic development reached a certain stage, the total farmland 
of a country or region may not necessarily show a recoverable net increase, but the net consumption rate of farmland will slow down or even stagnate significantly (Long et al., 2012a; Ge et al., 2018). Therefore, the transition of farmland can be understood as the process of a country or region's farmland changing from continuous and rapid consumption in the relatively low-level stage of socio-economic development to low-speed consumption and even stagnation in the relatively advanced stage of socio-economic development (Long et al., 2012a; Ge et al., 2018).

The total farmland and the annual net consumption rate are two major indicators for describing the dominant transition of farmland (Tan, 2014; Ge et al., 2018). Diagnosing the transformation of the spatial morphology of farmland can be started from exploring the turning point of the total area of farmland (Bertoni et al., 2018; Ge et al., 2018; You et al., 2018), which always fluctuates with policy reform, economic growth, and demographic change (Tan et al., 2009). The mutational point of farmland change includes the above-mentioned turning point. If after a certain time, the annual net consumption rate of farmland significantly slows down or even stagnates, indicating that the spatial transformation of farmland morphology occurred at that point. From the perspective of the spatial pattern, farmland is often fragmented and scattered at a lower level of socio-economic development. With the socio-economic advancement, it tends to be concentrated. The management pattern and landscape pattern are proved to be two major indicators for depicting farmland transition (Long et al., 2007). The farmland management pattern refers to the concentration of plots managed by farmers or other users (Long et al., 2016; Ma et al., 2020). It can be measured by the management scale, such as the area of farmland per agricultural employee, the number of plots per household, and farm size. The landscape pattern can be indicated by multiple landscape attributes, such as the number of patches, the density of patches, average areas of the patches, etc. Land use function also provides a meaningful perspective of examining farmland transition. The definition of farmland function links farmland with multiple demands. When considering the formation process, it is deduced from various human needs through the combined effects of land characteristics, human senses, and socio-economic systems (Lu et al., 2013). Generally, it can be classified into three categories-production function, ecological function and social function (Zhang et al., 2018).

\subsection{Rural housing land transition}

The connotations of rural housing land transition includes dominant transformations in quantity, space, and structure, and it should also fully reflect the changes in employment structure, lifestyle, and family structure corresponding with urban and rural development $\mathrm{Su}$ et al., 2011; Long et al., 2012a). The contradiction between humans and land is gradually highlighted, which facilitates relevant research to take a human into the framework (Qu et al., 2019). The research focusing on per capita rural housing land is the direct reflection, which is simultaneously affected by changes in the total area of housing sites and population migration (Qu et al., 2019). Contrary to the fact that rural housing land area has generally increased, induced by urbanization and industrialization, farmers have migrated to urban areas temporarily or completely, thus causing the increase of rural housing land and population decline (Long et al., 2019). Existing researches on rural housing land transition is rela- 
tively rare in China, which mainly concentrates on the spatial distribution, utilization status, mode for land consolidation, and its functional transition process (Jiang et al., 2016). Several types of the spatial distribution of rural settlements (Qu et al., 2017, 2018), such as clustering, random, and uniform discrete distribution, were found in China with significant regional differences (Yang et al., 2016). The spatial distribution studies involve various scales, national/regional level, city level, county level, and village level, and massive empirical researches have been finished in China (Ma et al., 2018). The utilization intensity of rural settlements is also highlighted under the context of the huge demand for land. Much attention has been given to the abandoned rural residential land (Zhang et al., 2019), which attempts to explore the spatial heterogeneity, influential factors, formation mechanism, and consolidation potential and mode. There are several pieces of research tried to theorize rural housing land transition by linking it with population mobility and urbanization process $(\mathrm{Qu}$ et al., 2019). Besides, it has been revealed that the function of rural housing land tends to be diversified (Zhu et al., 2014, 2018; Ma et al., 2019).

\subsection{Land use transitions and rural vitalization and restructuring}

Rural restructuring, which is internationally prevalent, has the most overlapped meanings with rural transformation development (Liu, 2011; Long, 2012b; Long and Liu, 2016). In the process of rural restructuring, the functional and structural transformation of the rural territorial system constitutes the interaction of land use transition and rural restructuring (Long and Liu, 2016; Tu and Long, 2017; Long, 2020). The research on land use transitions aims to reveal the non-linear change process of regional land use patterns (including dominant and recessive morphologies) (Long and $\mathrm{Qu}, 2018$ ), while the rural transformation development focuses on exploring the trend of the restructuring process (Hoggart and Paniagua, 2001). At different stages of socio-economic development, the characteristics of the man-land interrelations in the rural territorial system are significantly different (Hu et al., 2019b). Regional land use patterns and rural development status also show significant spatial and temporal heterogeneity. Researches have revealed that the change process of regional land use pattern conflict is the internal mechanism that drives the evolution of land use pattern (Long and Qu, 2018). The regional pattern of rural man-land interrelations corresponding to land use conflicts will also change, which has also become a key factor in determining the process of rural restructuring (Chen et al., 2012). Therefore, the conflict of regional land use patterns is closely related to the driving force of rural restructuring (Long et al., 2016). The response and feedback process of the regional pattern of rural man-land interrelations to the two forces constitutes a bridge between land use transitions and rural restructuring ( $\mathrm{Tu}$ and Long, 2017). Land use transition and its coupling and coordination process with rural restructuring is the key to rural vitalization ( $\mathrm{Liu}$ and $\mathrm{Li}, 2017$; $\mathrm{Liu}, 2018$ ). Land use transition studies provide a new perspective for an in-depth understanding of land use changes by characterizing the trend variation of land use patterns in both dominant and recessive states (Long, 2014b; Long and $\mathrm{Qu}, 2018)$. At the same time, significant changes have taken place in the rural population, land, industry, culture and society. In the process of urban-rural migration, land allocation between urban and rural, industry transformation and upgrading, and the evolution of a socio-cultural system are all deeply affected by the rural restructuring process.

Land use transition, a dynamic process, is driven by a set of forces, such as the input of 
capital and labor, industrial development, employment and population mobility, which have tight associations with rural restructuring (Figure 6). In turn, the status quo of land use can mirror various issues in the process of rural development. Usually, the spatio-temporal inseparability of socio-economic advancement is transferred to land, which is the main carrier of socio-economic activities, creating a very complex land use pattern. While, changes in this land use pattern will affect the process of regional natural, ecological and social development. In conclusion, land use transitions and rural restructuring are mutual feedback processes (Long and Tu, 2018; Long, 2020). Coordinating the coupling relationship between land use transitions and rural restructuring is of great significance for optimizing the rural transformation development process and the integrated development of the urban and the rural (Fang and Yu, 2016; Zhang et al., 2016; Tu et al., 2018).

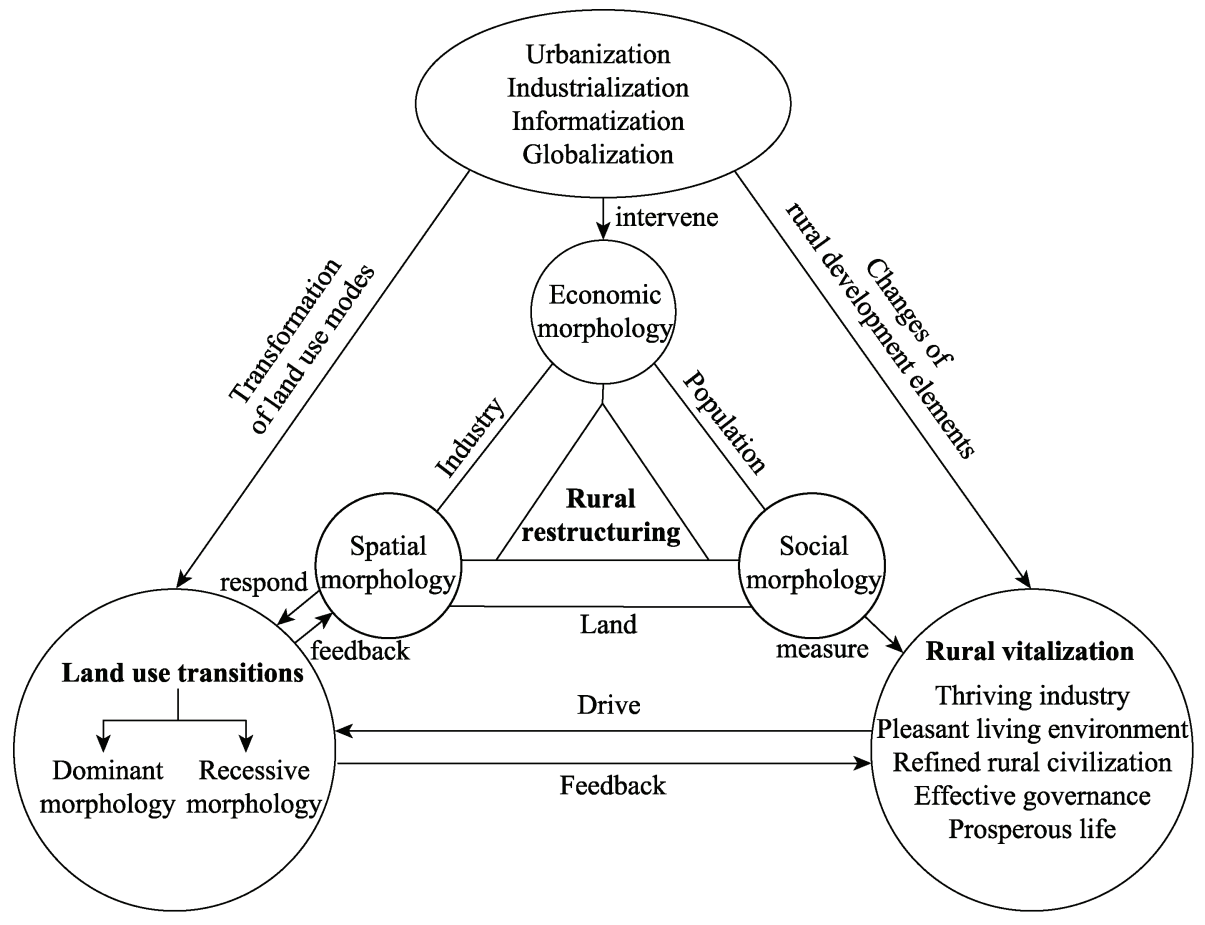

Figure 6 The relationship among land use transitions, rural vitalization and rural restructuring (Adapted from Long and Tu, 2018)

\section{Research prospects}

Currently, as an important measure to solve the issues relating to "agriculture, rural areas and farmers" in China, the double-wheel driving strategy of rural vitalization and new-type urbanization has put forward realistic demands of science and technology to realize the land use transitions successfully in rapid urbanization phase, which promotes an urgent requirement of theoretical innovation and academic achievements in agricultural geography and rural development as an strong support. Accordingly, the future research fields concerning land use transitions are suggested as follows (Long, 2012a, 2020):

(1) The dynamic patterns and territorial types of land use transitions. The dynamic pat- 
terns of regional land use transitions during the process of rapid urbanization could be depicted by establishing evaluation index systems and evaluation models. Focusing on the spatial allocation of factors and resources concerning rural development and the regional differentiations in the aspects of bio-physical geographical environment and socio-economic development, combining the evaluation results of regional dynamic patterns of land use transitions with relevant models is expected to identify the territorial types of land use transitions and to draw out the rules concerning the heterogeneous statuses of land use transitions related to regional socio-economic development differences. Meanwhile, based on the field investigations in typical areas, the natural, economic, social, political and cultural as well as the institutional factors affecting land use transitions in different territorial types, the stage characteristics, problems and their major influential factors of land use transitions are necessary to be analyzed.

(2) The interactions and dynamic mechanism of land use transitions and rural transformation development. Focused on the typical regional types of land use transitions and rural transformation development, the changing patterns and trends of the major driving factors (including land, capital, labor force and industrial development) could be analyzed and revealed in combination with field investigations and modelling simulations, from the perspectives of changes in regional natural-ecological structure, technological-economic structure and social-political structure, to qualitatively and quantitatively investigate the dominant driving force and interacting mechanism as well as the coupling relationship and its dynamic mechanism leading to the transformation of the stages of land use transitions.

(3) The resources and environmental effects of land use transitions. Under the background of rapid urbanization, there is an urgent need to study the value manifestation and proliferation effects concerning the flows of rural development elements in the process of land use transitions, and the systematical assessment of the influential process, intensity and effects of some new factors including rapid industrialization and urbanization development, and the formulation and deployment of national strategies and policies supporting and benefiting agriculture and rural areas on sustainable rural development at the scales of village and farmer. Furthermore, a series of indices system and integrated assessing models need to be established based on the rural physical and social environment elements to measure and evaluate the resources and environmental effects of land use transitions on local rural territorial system.

(4) The modes and paths of adjusting and controlling land use transitions. By integrating the time scale and historical background of social and environmental changes, the optimizing and adjusting modes of land use transitions during the process of rapid urbanization can be summarized and extracted. From the theoretical perspective of rural system growth and urban-rural interactive development, how to follow the rural transformation development in the new era and improve the capability of rural territories with different development types and degrees to adapt to the domestic and abroad competitive markets and their own development via adjusting and controlling land use transitions needs to be further discussed. Also, the paths to enhance rural productivity by spatial recombination of essential factors and resources favoring rural development and to facilitate urban-rural coordinated socio-economic development are also pivotal to the research of land use transitions. In addition, the recessive morphology of land use and its changes should become the focus of future research on land 
use transitions and land resource management. Managing and controlling the changes of recessive morphology of land use contributes to innovating the policies, regulations and institutions of land resource management and accelerating the transformation of land resource management in China from the simple management of quantity to the comprehensive management with equal emphasis on quantity, quality and ecology as well as the change from the simple resources management to the comprehensive resource-asset-capital management, so as to optimizingly allocate and sustainably use land resource in both the urban and the rural.

(5) The approaches of rural vitalization and restructuring promoted by land use transitions. Different economic and social development stages correspond to different land use patterns and land use transitions stages. Socio-economic development inevitably results in a specific land use transition process. Rural restructuring is an important means to implement the strategy of rural vitalization, also the link between land use transitions and rural vitalization. Population, land and industry are closely interlinked, and economy, space and society are intertwined. It is a complex and systematic project to realize rural vitalization relying on land use transitions and rural restructuring. The recessive morphology of land use and its changes should be the focus of research on rural vitalization through controlling land use transitions. Linking the revitalization of land resources with the rural industry is of great significance for the sustainable development of rural economy and the efficient use of resources. Therefore, it is an urgent need to innovate land management policies and regulations by controlling recessive morphology changes of land use, and to explore a new land use transition mode combined with multifunctional agriculture to promote rural vitalization.

\section{Conclusions}

With the in-depth research of land use transitions, the concept and connotations of land use morphology were further developed and expanded as two kinds, i.e., dominant morphology and recessive morphology. The dominant land use morphology refers to the quantity, structure and spatial pattern of land use, and the recessive land use morphology includes the land use features in the aspects of quality, property rights, management mode, fixed input, productive ability and function, etc. Accordingly, the concept of land use transition may be further developed as the changes in land use morphologies, including dominant morphology and recessive morphology, of a certain region over a certain period of time driven by socio-economic change and innovation, and it usually corresponds to the transformation of the socio-economic development stage.

Accordingly, the theoretical model of regional land use transitions is established as follows: with the economic and social development, transformations between different land use types during a certain period of time cause the change of the conflicts resulted from changed regional land use morphology pattern from strong to weak, i.e., a trend towards coordination; these transformations will lead to a new balance of regional land use morphology pattern consisting of different land use types which reflect the development trend of corresponding economic departments, respectively, and finally realize the qualitative transformation of urban-rural land use system.

The extension of land use morphology brings about opportunities and challenges as the 
qualitative aspect of land use transitions is reflected by the changes of recessive land use morphology, especially the changes of functions of land use system driven by the comprehensive variations in the aspects of quality, property rights, management mode, input and output of land use, which is difficult to be measured or represented. As such, this paper puts forward three innovative integrated approaches to study land use transitions, i.e., multidisciplinary research framework for recessive land use transition, transect research method, and horizontal comparison research method.

With the introduction of land use transition research into China, related researches combining land use transitions with the sustainability of rural China have been carried out extensively, which enrich the knowledge of land system science. The research fields majorly focus on farmland transition, rural housing land transition and their relationships with rural restructuring under the context of urbanization, industrialization and rural vitalization, which adapt the concept of land use transition derived from western literature to the situations and experiences in China.

\section{References}

Barbier E B, Burgess J C, Grainger, A, 2010. The forest transition: Towards a more comprehensive theoretical framework. Land Use Policy, 27(2): 98-107.

Bertoni D, Aletti G, Ferrandi G et al., 2018. Farmland use transitions after the CAP greening: A preliminary analysis using Markov Chains approach. Land Use Policy, 79: 789-800.

Cai Y, 2001. A study on land use/cover change: The need for a new integrated approach. Geographical Research, 20(6): 645-652. (in Chinese)

Cai Y, Wang Y, Li Y, 2009. Study on changing relationship of demand and supply of cultivated land in China. China Land Science, 23(3): 11-18, 31. (in Chinese)

Calogero C, Savastano S, Zezza A, 2013. Fact or artifact: The impact of measurement errors on the farm size-productivity relationship. Journal of Development Economics, 103: 254-261.

Chen C, 1998. Theories and Empirical Studies of Regional Comprehensive Development. Beijing: Science Press. (in Chinese)

Chen K, Long H, Liao L et al., 2020. Land use transitions and urban-rural integrated development: Theoretical framework and China's evidence. Land Use Policy, 92: 104465.

Chen R, Ye C, Cai Y et al., 2014. The impact of rural out-migration on land use transition in China: Past, present and trend. Land Use Policy, 40: 101-110.

Chen Y, Zhang Y, Liu Y, 2012. Regional differences of agricultural development in a typical transect in Jiangsu Province. Geographical Research, 29(7): 1317-1323. (in Chinese)

Chen Z, Huffman W E, Rozelle S, 2011. Invrese relationship between productivity and farm size: The case of China. Contemporary Economic Policy, 29(4): 580-592.

Fan J, 2019. The progress and characteristics of Chinese human geography over the past 70 years. Scientia Sinica Terrae, 49(11): 1697-1719. (in Chinese)

Fang C, Yu D, 2016. China's New Urbanization. Beijing: Science Press \& Spriner Press.

Ferreira M P, Alves D S, Shimabukuro Y E, 2015. Forest dynamics and land-use transitions in the Brazilian Atlantic Forest: The case of sugarcane expansion. Regional Environmental Change, 15(2): 365-377.

Foley J A, DeFries R, Asner G P et al., 2005. Global consequences of land use. Science, 309(5734): 570-574.

Fu B, 2014. The integrated studies of geography: Coupling of patterns and processes. Acta Geographica Sinica, 69(8): 1052-1059. (in Chinese)

Ge D, Long H, Zhang Y et al., 2018. Farmland transition and its influences on grain production in China. Land Use Policy, 70: 94-105. 
GLP (Global Land Project), 2005. Global Land Project: Science Plan and Implementation Strategy. IGBP Report No. 53/IHDP Report No.19, IGBP Secretariat, Stockholm.

Grainger A, 1986. The future role of the tropical rain forests in the world forest economy [D]. Oxford: University of Oxford.

Grainger A, 1995. National land use morphology: Patterns and possibilities. Geography, 80(3): 235-245.

Harvey D, 1969. Explanation in Geography. London: Edward Arnold.

Heltberg R, 1998. Rural market imperfections and the farm size-productivity relationship: Evidence from Pakistan. World Development, 26(10): 1807-1826.

Hoggart K, Paniagua A, 2001. What rural restructuring? Journal of Rural Studies, 17(1): 41-62

$\mathrm{Hu} \mathrm{S}$, Tong L, Long H, 2019a. Land use transition potential and its assessment framework. Geographical Research, 38(6): 1367-1377. (in Chinese)

$\mathrm{Hu}$ X, Li H, Zhang X et al., 2019b. Multi-dimensionality and the totality of rural spatial restructuring from the perspective of the rural space system: A case study of traditional villages in the ancient Huizhou region, China. Habitat International, 94: 102062.

Jadin I, Meyfroidt P, Lambin E, 2016. International trade, and land use intensification and spatial reorganization explain Costa Rica's forest transition. Environmental Research Letters, 11(3): 035005.

Jiang G, He X, Qu Y, Zhang R et al., 2016. Functional evolution of rural housing land: A comparative analysis across four typical areas representing different stages of industrialization in China. Land Use Policy, 57: 645-654.

Koch G W, Scholes R J, Steffen W L et al., 1995. The IGBP Terrestrial Transects: Science Plan. IGBP Reports No.36, IGBP Secretariat, Stockholm.

Kong X, 2012. The Influence of Land Use Transition of Regional Peasant Household on Farmland Quality. Beijing: Science Press

Krausmann F, Haberl H, Schulz N B et al., 2003. Land-use change and socio-economic metabolism in Austria (Part I): Driving forces of land-use change: 1950-1995. Land Use Policy, 20(1): 1-20.

Lambin E F, 2012. Global land availability: Malthus versus Ricardo. Global Food Security, 1(2): 83-87.

Lambin E F, Meyfroidt P, 2010. Land use transitions: Socio-ecological feedback versus socio-economic change. Land Use Policy, 27(2): 108-118.

Li X, 1996. A review of the international researches on land use/land cover change. Acta Geographica Sinica, 63(6): 553-558. (in Chinese)

Li X, 2002. Explanation of land use changes. Progress in Geography, 21(3): 195-203. (in Chinese)

Liu C, Li X, 2006. Regional differences in the changes of the agricultural land use in China during 1980-2002. Acta Geographica Sinica, 61(2): 139-145. (in Chinese)

Liu Y, 2011. Geography of New Countryside Construction in China. Beijing: Science Press. (in Chinese)

Liu Y, 2018. Research on the urban-rural integration and rural revitalization in the new era in China. Acta Geographica Sinica, 73(4): 637-650. (in Chinese)

Liu Y, Li Y, 2017. Revitalize the world's countryside. Nature, 548(7667): 275-277.

Liu Y, Liu Y, Chen Y et al., 2010. The process and driving forces of rural hollowing in China under rapid urbanization. Journal of Geographical Sciences, 20(6): 876-888.

Liu Y, Wang L, Long H, 2008. Spatio-temporal analysis of land-use conversion in the eastern coastal China during 1996-2005. Journal of Geographical Sciences, 18(3): 274-282.

Long H, 2001. Land use changes and sustainable land management in transect of the Yangtse River [D]. Beijing: IGSNRR, CAS. (in Chinese)

Long H, 2003. Land use transition: A new integrated approach of land use/cover change study. Geography and Geo-information Science, 19(1): 87-90. (in Chinese)

Long H, 2012a. Land use transition and rural transformation development. Progress in Geography, 31(2): 131-138. (in Chinese)

Long H, 2012b. Land Use and Rural Transformation Development in China. Beijing: Science Press. (in Chinese)

Long H, 2014a. Land consolidation: An indispensable way of spatial restructuring in rural China. Journal of Ge- 
Geographical Sciences, 24(2): 211-225.

Long H, 2014b. Land use policy in China. Land Use Policy, 40: 1-146.

Long H, 2015. Land use transition and land management. Geographical Research, 34(9): 1607-1618. (in Chinese)

Long H, 2020. Land Use Transitions and Rural Restructuring in China. Singapore: Springer Nature.

Long H, Ge D, Zhang Y et al., 2018a. Changing man-land interrelations in China's farming area under urbanization and its implications for food security. Journal of Environmental Management, 209: 440-451.

Long H, Heilig G K, Li X et al., 2007. Socio-economic development and land-use change: Analysis of rural housing land transition in the Transect of the Yangtse River, China. Land Use Policy, 24: 141-153.

Long H, Li T, 2012. The coupling characteristics and mechanism of farmland and rural housing land transition in China. Journal of Geographical Sciences, 22(3): 548-562.

Long H, Li X, 2002. Analysis on regional land use transition: A case study in transect of the Yangtze River. Journal of Natural Resources, 17(2): 144-149. (in Chinese)

Long H, Li Y, Liu Y et al., 2012a. Accelerated restructuring in rural China fueled by 'increasing vs. decreasing balance' land-use policy for dealing with hollowed villages. Land Use Policy, 29(1): 11-22.

Long H, Liu Y, 2016. Rural restructuring in China. Journal of Rural Studies, 47 (Part B): 387-676.

Long H, Liu Y, Li X et al., 2010. Building new countryside in China: A geographical perspective. Land Use Policy, 27: 457-470.

Long H, Qu Y, 2018. Land use transitions and land management: A mutual feedback perspective. Land Use Policy, 74: $111-120$.

Long H, Qu Y, Tu S et al., 2018b. Land use transitions under urbanization and their environmental effects in the farming areas of China: Research progress and prospect. Advances in Earth Science, 33(5): 455-463. (in Chinese)

Long H, Tu S, 2018. Land use transition and rural vitalization. China Land Science, 32(7): 1-6. (in Chinese)

Long H, Tu S, Ge D et al., 2016. The allocation and management of critical resources in rural China under restructuring: Problems and prospects. Journal of Rural Studies, 47: 392-412.

Long H, Zhang Y, Tu S, 2019. Rural vitalization in China: A perspective of land consolidation. Journal of Geographical Sciences, 29(4): 517-530.

Long H, Zou J, Li T et al., 2012b. Study on the characteristics and territorial types of rural transformation development: The case of "Southern Jiangsu-Northern Shaanxi" transect. Geographical Research, 31(3): 144-149. (in Chinese)

Lu D, Shi P, Dong G, 2006. Important ideas embodying land use transition. China Land and Resources News, 2006/07/17/005. (in Chinese)

Lu S, Guan X, Liu Y et al., 2013. Agricultural region type identification and its spatio-temporal evolution characteristics: A case study of sampling belt along G106 in China. Progress in Geography, 32(4): 637-648. (in Chinese)

Lu S, Liu Y, 2013. Rural land consolidation potential of typical transect along No.106 state road. Journal of Natural Resources, 28(4): 537-549. (in Chinese)

Ma L, Long H, Tu S et al., 2020. Farmland transition in China and its policy implications. Land Use Policy, 92 : 104470 .

Ma W, Jiang G, Li W et al., 2019. Multifunctionality assessment of the land use system in rural residential areas: Confronting land use supply with rural sustainability demand. Journal of Environmental Management, 231: 73-85.

Ma W, Jiang G, Zhang R et al., 2018. Achieving rural spatial restructuring in China: A suitable framework to understand how structural transitions in rural residential land differ across peri-urban interface? Land Use Policy, 75: 583-593.

Mather A S, Fairbairn J, Needle C L, 1999. The course and drivers of the forest transition: The case of France. Journal of Rural Studies, 15(1): 65-90.

Meyfroidt P, Lambin E F, 2008. The causes of the reforestation in Vietnam. Land Use Policy, 25(2): 182-197. 
Meyfroidt P, Lambin E F, Erb K H et al., 2013. Globalization of land use: Distant drivers of land change and geographic displacement of land use. Current Opinion in Environmental Sustainability, 5(5): 438-444.

Nuissl H, Haase D, Lanzendorf M et al., 2009. Environmental impact assessment of urban land use transitions: A context-sensitive approach. Land Use Policy, 26(2): 414-424.

Qu Y, Jiang G, Li Z et al., 2019. Understanding rural land use transition and regional consolidation implications in China. Land Use Policy, 82: 742-753.

Qu Y, Jiang G, Yang Y et al., 2018. Multi-scale analysis on spatial morphology differentiation and formation mechanism of rural residential land: A case study in Shandong Province, China. Habitat International, 71: 135-146.

Qu Y, Jiang G, Zhao Q et al., 2017. Geographic identification, spatial differentiation, and formation mechanism of multifunction of rural settlements: A case study of 804 typical villages in Shandong Province, China. Journal of Cleaner Production, 166: 1202-1215.

$\mathrm{Qu}$ Y, Long H, 2018a. The economic and environmental effects of land use transitions under rapid urbanization and the implications for land use management. Habitat International, 82: 113-121.

Qu Y, Long H, 2018b. A framework of multi-disciplinary comprehensive research on recessive farmland transition in China. Acta Geographica Sinica, 73(7): 1226-1241. (in Chinese)

Rudel T K, Schneider L, Uriarte M, 2010. Forest transitions: An introduction. Land Use Policy, 27(2): 95-97.

Song X, 2017. Discussion on land use transition research framework. Acta Geographica Sinica, $72(3)$ : $471-487$. (in Chinese)

Song X, Huang Y, Wu Z et al., 2015. Does cultivated land function transition occur in China? Journal of Geographical Sciences, 25(7): 817-835.

Song X, Li X, 2019. Theoretical explanation and case study of regional cultivated land use function transition. Acta Geographica Sinica, 75(4): 992-1010. (in Chinese)

Su S, Zhang Q, Zhang Z et al., 2011. Rural settlement expansion and paddy soil loss across an ex-urbanizing watershed in eastern coastal China during market transition. Regional Environmental Change, 11(3): 651-662.

Tan M, 2014. The transition of farmland production functions in metropolitan areas in China. Sustainability, 6(7): 4028-4041.

Tan R, Beckmann V, van den Berg L et al., 2009. Governing farmland conversion: Comparing China with the Netherlands and Germany. Land Use Policy, 26(4): 961-974.

Tu S, Long H, 2017. Rural restructuring in China: Theory, approaches and research prospect. Journal of Geographical Sciences, 27(10): 1169-1184.

Tu S, Long H, Zhang Y et al., 2018. Rural restructuring at village level under rapid urbanization in metropolitan suburbs of China and its implications for innovations in land use policy. Habitat International, 77: $143-152$.

Yang R, Xu Q, Long H, 2016. Spatial distribution characteristics and optimized reconstruction analysis of China's rural settlements during the process of rapid urbanization. Journal of Rural Studies, 47: 413-424.

You H, Hu X, Wu Y, 2018. Farmland use intensity changes in response to rural transition in Zhejiang province, China. Land Use Policy, 79: 350-361.

Zhang B, Sun P, Jiang G et al., 2019. Rural land use transition of mountainous areas and policy implications for land consolidation in China. Journal of Geographical Sciences, 29(10): 1713-1730.

Zhang Q, Sun Z, Wu F et al., 2016. Understanding rural restructuring in China: The impact of changes in labor and capital productivity on domestic agricultural production and trade. Journal of Rural Studies, 47: 552-562.

Zhang Y, Long H, Ma L et al., 2018. Farmland function evolution in the Huang-Huai-Hai Plain: Processes, patterns and mechanisms. Journal of Geographical Sciences, 28(6): 759-777.

Zhu F, Zhang F, Ke X, 2018. Rural industrial restructuring in China's metropolitan suburbs: Evidence from the land use transition of rural enterprises in suburban Beijing. Land Use Policy, 74: 121-129.

Zhu F, Zhang F, Li C et al., 2014. Functional transition of the rural settlement: Analysis of land-use differentiation in a transect of Beijing, China. Habitat International, 41: 262-271. 